\title{
Development of the Higher Education Value Inventory: Factor Structure and Score Reliability
}

\author{
Vickie R. Luttrell ${ }^{1}$, David C. S. Richard ${ }^{2}$ \\ ${ }^{1}$ Department of Behavioral Sciences, Drury University, Springfield, USA; \\ ${ }^{2}$ Department of Psychology, Rollins College, Winter Park, USA \\ Email: vluttrel@drury.edu \\ Received September $16^{\text {th }}, 2011$; revised October 11 $1^{\text {th }}, 2011$; accepted November $24^{\text {th }}, 2011$.
}

\begin{abstract}
Students bring to college a value system that affects their levels of academic achievement and persistence. The goal of this project was to develop a self-report inventory that measures the value students place on higher education. The Higher Education Value Inventory (HEVI) surveys students' attitudes and behaviors in five domains: family expectations, scholastic focus, achievement value, general education value, and achievement obstacles. We describe the development of the HEVI and report the results of reliability studies and factor analyses. HEVI scores accounted for $35.9 \%$ of the variance in freshman grades. Implications for educational researchers and admissions officers are provided
\end{abstract}

Keywords: Expectancy-Value Theory, Task Value, Motivation, College Students

\section{Introduction}

Researchers in higher education seek comprehensive theories of learning and instruction to guide their daily work. Our philosophy has been shaped by Piaget (1928/2009), Ausubel (1968), and Novak (1977) who emphasized that what the learner already knows and values are among the most important influences on behavior. According to Rokeach (1979) and Schwartz (1992, 2010), values are transcendent core beliefs that, when activated, serve as standards that guide our actions, choices, judgments, and justifications. Values mediate students' decision-making as they pursue scholastic activities (Feather, 1982) and are related to motivation in the sense that the value one instills in a behavior functionally determines the strength with which the behavior is pursued (Rheinberg, Vollmeyer, \& Rollett, 2000).

Given that students bring to college a value system that can affect their levels of engagement and persistence, students' values have been investigated extensively. Rotter (1954) and Atkinson (1957) proposed that students' expectancies for success and the inherent value they place on that success interactively mediate achievement-related behavior. Unfortunately, investigations of college academic achievement using Rotter's theoretical framework have focused almost exclusively on the expectancy component (i.e., locus of control) of the expectancy-value dichotomy (e.g., Findley \& Cooper, 1983; Kalechstein \& Nowicki, 1997). This is problematic because even if students are certain they can master certain tasks, they may have little incentive to do so (Eccles \& Wigfield, 2002).

Grounded in the seminal work of Atkinson (1957), Eccles et al. (1983) and Eccles, Adler, and Meece (1984) developed a comprehensive model of achievement-related choices, which highlighted the multidimensional nature of task value as well as its importance as a proximal predictor of behavior. They proposed that task value is reflected in students' interest in a task (intrinsic value), its importance to them (attainment value), its utility for them (utility value), and its cost. Using confirmatory factor analysis, Eccles and Wigfield (1995) demonstrated that the three value components could be differentiated in the mathematics domain, supporting the construct validity of their model.

Most empirical tests of Eccles et al.'s (1983, 1984) expectancy-value theory have been done with children and adolescents. Researchers have devoted most of their attention to studying relationships between task value and math participation, and findings across studies are consistent. Math value has been shown to predict grades in math (Berndt \& Miller, 1990), course enrollment intentions (Meece, Wigfield, \& Eccles, 1990), number of math courses taken (Simpkins, Davis-Kean, \& Eccles, 2006; Updegraff, Eccles, Barber, \& O’Brien, 1996), difficulty of math courses completed (Nagy, Trautwein, Baumert, Köller, \& Garrett, 2006; Watt, Eccles, \& Durik, 2006), mathrelated career aspirations (Jozefowicz, Barber, \& Eccles, 1993; Watt, 2006), and plans to attend college (Eccles, Vida, \& Barber, 2004). Longitudinal changes in task value across the elementary and secondary years have also been studied extensively (e.g., Jacobs, Lanza, Osgood, Eccles, \& Wigfield, 2000). Research involving college students (e.g., Battle \& Wigfield, 2003; Bong, 2001; Chiu, Sun, Sun, \& Ju, 2007; Feather, 1988; Frome, Alfeld, Eccles, \& Barber, 2006; Platt, 1988; VanZile-Tamsen, 2001) has been less common, but results highlight the importance of the values construct in higher educational research.

\section{Rationale for the Higher Education Value Inventory (HEVI)}

Value, expressed as a verb, refers to the process of appraising the worth of some commodity (Rohan, 2000). Guided by the premise that the value construct should occupy a central position in research on motivation and cognizant of the expectancyvalue framework, the purpose of our study was to develop a self-report inventory that measures the value students place on higher education. Fundamentally, we hypothesized that those students who placed greater value on higher education would evidence greater academic achievement and be more likely to matriculate through an undergraduate curriculum. A goal from the outset, therefore, was to make the HEVI unique in its assessment of the degree to which college students value their 
education in a general sense. An instrument that facilitated this assessment would be of considerable assistance to admissions officers interested in estimating a student's likelihood of completing an undergraduate degree.

In addition to its potential utility in admissions decisionmaking, the HEVI can provide a means to assess the relationship between higher education value and academic achievement and/or retention. Also, the inventory could facilitate examination of longitudinal changes in students' valuing of higher education over the course of their undergraduate experience. Longitudinal studies may provide insight into why certain students remain motivated to achieve and persist while others become disinterested and drop out (Neuville et al., 2007). Finally, when used alone or in conjunction with expectancy measures, the HEVI might incrementally increase prediction of undergraduate success and retention afforded by high school GPA or standardized achievement scores.

Haynes, Richard, and Kubany (1995) and the Standards for Educational and Psychological Testing (American Educational Research Association, American Psychological Association, \& National Council on Measurement in Education, 1999) suggest that to maximize validity, researchers should take into consideration their intended population of test takers when designing and/or selecting assessment tools. Although questionnaires have been developed to study perceived value (e.g., Eccles et al., 1983, Lupart, Cannon, \& Telfer, 2004), they were unsuitable for our purposes because they were designed for younger students and focused on discrete subject areas, to include math, science, English, and computer usage. Given our focus on entering freshman students and our understanding that value priorities may differ for students of traditional and nontraditional-age (e.g., Faust \& Courtenay, 2002; Hermon \& Davis, 2004; Jinkens, 2009), our target population includes traditional-age freshman students, who are 18 to 24 years old.

\section{Study 1: Development of the HEVI Item Pool and Item Tryout}

\section{Content Domain Specification, Identification of Facets, and Item Generation}

We conceptualized the higher education values domain as encompassing those values that bear directly on a person's motivation for excelling in postsecondary education. The value domain was composed of five facets. Four of the facets were based on the work of Eccles et al. $(1983,1984)$ and were tentatively labeled interest value, utility value, attainment value, and perceived cost. An additional facet, family expectations, was included to tap important family and social influences on an individual's appraisal of worth.

We defined interest value as the enjoyment or satisfaction derived by an individual from participating in school-related activities. Interest value is conceptually similar to intrinsic motivation; consequently, if a task has high interest value, one is intrinsically motivated to perform it (Eccles et al., 1983). We defined utility value as the value an individual places on a task or activity due to its instrumentality in achieving one or more short- and long-range goals. Although a task high in utility value may not be intrinsically interesting, it may still be valued because of its perceived effects on one's personal or professional achievement (Husman \& Lens, 1999; Kauffman \& Husman, 2004). We defined attainment value as the value a person places on doing well in school. The perceived value of grades has been found to be a statistically significant predictor of GPA even when standardized test scores are controlled (Pollio, Eison, \& Milton, 1988; Valencia, 1997).

We defined perceived cost as the subjective estimate of loss suffered by an individual as a result of engaging in schoolrelated activities. If the perceived costs of educational attainment outweigh the perceived benefits, scholastic success may be devalued. For example, a person may devalue education if it is perceived as conflicting with or inhibiting development of identity, interpersonal relationships, immediate financial income, or other incompatible but valued activities. Finally, we defined family expectations as a student's perception of family expectations for his or her academic achievement. The family expectations facet was included as a component of the higher education values domain based on findings that values and achievement-related choices are a function of the value orientations of parents and significant others (Ferry, Fouad, \& Smith, 2000; Frome \& Eccles, 1998; Jacobs \& Harvey, 2005; Reynolds \& Burge, 2008).

Drawing from Feather (1988), Schwartz (1992), and Rohan (2000), we recognized that underlying a behavior is a trade-off between competing value priorities. We conceptualized interest value, utility value, attainment value, and family expectations as characteristics that would increase the perceived value of attending college. Perceived cost was conceptualized in terms of factors that would detract from that value. With these relationships in mind, we rationally constructed 76 Likert-type items to reflect each of the five facets. Response options ranged from 0 (Strongly disagree) to 4 (Strongly agree).

\section{Method}

\section{Participants and Procedure}

The initial version of the HEVI was administered to 781 undergraduates at a large state university in the Midwest. Participants completed the informed consent, a demographic questionnaire, and the inventory. Given our educational focus, however, only those inventories completed by freshmen under the age of 25 were analyzed. Given these inclusion criteria, the final sample consisted of 305 freshmen (173 women and 132 men). Participants ranged in age from 18 to 24 years $(M=$ $18.79, S D=.90)$ and included 277 Whites, 14 Blacks, 6 Asians, 3 Hispanics, and 5 students self-classified as "Other". Completion times averaged about 20 minutes.

\section{Statistical Analyses}

Items were evaluated in terms of skewness, kurtosis, and inter-item correlations. Items were rejected if the ratio of skewness and/or kurtosis to their respective standard errors (e.g., skewness index/standard error of skewness) was greater than \pm 2.00 . Items with nonnormal distributions were eliminated, and highly intercorrelated items $(r \geq .80)$ were examined for redundancy of content.

Based on recommendations by Floyd and Widaman (1995), we subjected data to a principal components analysis (PCA). The number of components to be retained was determined via visual inspection of a scree plot and component eigenvalues greater than 1. Retained components were subjected to varimax rotation (Kaiser, 1958) and decisions regarding item retention were based on structure coefficients reported in the rotated component matrix. Following the recommendations of Comrey (1973) and Stevens (2002), we set the coefficient criterion to .45 to ensure that a constituent item correlated significantly with its respective component and minimally shared $20 \%$ of its variance with the component. In order to minimize component 
overlap, we excluded items with complex coefficients. An item with complex coefficients was defined as an item that loaded $\geq .45$ on one component and $\geq .30$ on one or more other components. Excluding these items maximized the unidimensionality and internal consistency of scores on each subscale. Regarding internal consistency, Nunnally and Bernstein (1994) advised that alpha coefficients should reach or exceed .70 during preliminary scale development. Therefore, scales with alpha coefficients of . 70 were determined to show an acceptable degree of item interrelatedness.

\section{Results}

Seven of the 76 items were removed from the pool based on extreme skewness and/or kurtosis. The remaining 69 items were subjected a PCA (Cattell, 1966). We removed 42 items for the following reasons: initial communality below $.20(n=8)$, item failure to obtain a coefficient of .45 or greater on any component $(n=12)$, or complex items $(n=22)$. We ran the analysis a second time using the remaining 27 items. Five principal components accounted for $49.29 \%$ of variance explained.

After inspecting the items, we assigned content-relevant labels to the components. The five components were named as follows (original theoretically-derived facet labels appear parenthetically): Scholastic Focus (9 items; interest value), General Education Value (8 items; utility value), Achievement Value (5 items; attainment value), Competing Obligations or Obstacles (3 items; personal cost) and Others' Expectations (Family Expectations; 2 items). Although the conceptual similarity between the factor labels and their respective facet may seem obvious, the revised factor labels better reflected the content of the actual items. Regarding internal consistency, coefficient alphas for scores on the Scholastic Focus, General Education Value, Achievement Value, Competing Obligations or Obstacles subscales, and Others' Expectations were $\alpha$ $=.84, .77, .77, .63$, and .62 , respectively.

\section{Study 2: Item Refinement and Final Scale Construction}

In preparation for the second item tryout, we generated 26 new items to enhance the measurement of each facet, bringing the total number of items to 53 . We then asked six undergraduate students to evaluate the 53 items for meaning and clarity of content. After receiving information about the purpose of the HEVI and descriptions of each facet, students independently rated the wording of each item by way of a dichotomous rating scale (i.e., clearly written items were rated 1 , while items requiring revision were rated 0 ). In the case of a revision, students were asked to provide recommendations. Students also had the option of generating additional items for any or all of the five facets. Students judged 11 of the 53 items to be written unclearly, and those items were revised. Students provided no new item suggestions for inclusion in the pool.

Providing evidence for content validity requires multiple experts to assess the degree to which items represent the facets of interest (Haynes et al., 1995). Therefore, we selected five university professors, who specialized in testing and measurement to participate in an item-sorting task. For the sorting task, we typed each item on an index card. Labels representing each of the five facets were also typed on individual cards, with an extra card labeled "Other." Using descriptions of the five facets as guides, experts attempted to sort each item into the facet that seemed logically most appropriate. If an item did not seem to fit logically into any of the facets, we instructed them to sort it into the "Other" category. Items failing to be assigned to the same facet by at least $80 \%$ (or 4 out of 5) of the experts were eliminated from the item pool. Experts were also asked to generate additional items for any or all of the five facets. As a result of the task, we excluded 3 of the 53 items because they were sorted into multiple facets. Experts provided no recommendations for additional items.

After having students and experts review the item pool in its entirety, we administered the HEVI to a large sample of undergraduates and conducted a PCA in a manner similar to that reported in Study 1. In addition, we took a preliminary look at convergent validity by regressing HEVI subscale scores on self-reported GPAs and also tested for gender-related differences in HEVI performance.

\section{Participants}

A total of 560 students agreed to participate, but only those inventories completed by freshmen under the age of 25 were analyzed. Given these inclusion criteria, the final sample consisted of 326 freshmen (180 women and 146 men). This produced a participant-to-item ratio of 6.52 , which is consistent with published recommendations (Gorsuch, 1997; Guadagnoli $\&$ Velicer 1988). Participants ranged in age from 17 to 24 years $(M=18.79, S D=.86)$ and included 302 Whites, 7 Blacks, 9 Asians, 3 Hispanics, and 6 students self-classified as "Other". Completion times averaged approximately 10 minutes.

\section{Procedure and Statistical Analyses}

Items were evaluated for skewness, kurtosis, and redundancy of content, and data were subjected to a PCA. We also examined the correlation between subscale scores and self-reported overall GPA and conducted a standard multiple regression analysis. Scores on the five HEVI subscales served as predictors and overall self-reported GPA was the criterion. The standard multiple regression procedure, where all predictor variables remain in the model, was selected so that the value of the entire set of HEVI predictors could be evaluated. Finally, men's and women's scale scores as well as self-reported GPAs were compared by way of two-tailed independent-sample $t$-tests.

\section{Results}

\section{Item and Principal Component Analyses}

The 50 HEVI items were examined initially for normality of response distributions. One item was excluded because of extreme skewness and kurtosis. Because the purpose of this study was to reduce the number of HEVI items to a final set, PCA was considered the most appropriate exploratory method available (Floyd \& Widaman, 1995). Subsequent to conducting the PCA, we conducted a common factor analysis using maximum likelihood extraction with varimax rotation to investigate whether the two procedures led to any meaningful differences in structure coefficients and variance accounted for in the respective solutions.

Based on observation of the scree plot, five factors were extracted and subjected to varimax rotation with Kaiser Normalization (Kaiser, 1958). We removed 16 items for the following reasons: initial communality below $.20(n=3)$, failure for an item to achieve the coefficient criterion of .45 or greater on any of the five components $(n=8)$, and complex coefficients $(n=$ 5 ). To produce an inventory with equal-item subscales, we retained the six items that evidenced the highest coefficients for each of the five components, resulting in a 30 -item inventory. 
We conducted a PCA again with these 30 items. Total variance explained was $53.12 \%$. One item ("I love school.") failed to reach the .45 coefficient criterion for Factor IV; however, the decision was made to retain this item after we found the item contributed positively to the alpha coefficient for the subscale.

We calculated scale scores by summing scores on constituent items. Overall, factor correlations were small, with only one correlation exceeding .30. Given the small intercorrelations and the greater interpretability of orthogonal rotations relative to oblique rotations, our use of varimax rotation was justified (see Nunnally \& Bernstein, 1994). However, given that 5 of the 10 factor intercorrelations were statistically significant, we subjected the retained factors to oblique (promax) rotation to see if meaningful differences emerged. The underlying factor structure remained unchanged. Thus, we report results from the PCA for the final 30 items, subscale descriptive statistics, Cronbach alphas, and component correlations in Table 1 .

\section{Regression Analysis}

Scores on four of the five subscales correlated statistically with self-reported GPA, including Scholastic Focus, $r(318)$ $=.22, p<.001$, Achievement Value, $r(317)=.54, p<.001$, General Education Value, $r(317)=.23, p<.001$, and Achievement Obstacles, $r(319)=.23, p<.001$. Self-reported GPA also statistically correlated with HEVI Total Score, $r(306)=.39, p$ $<.001$. It is important to note that higher scores on Achievement Obstacles reflected fewer perceived obstacles to achievement; therefore, consistent with logical predictions, fewer achievement obstacles was related to higher GPAs. Only the Family Expectations subscale did not reach statistical significance, $r(318)=.05, p=.353$.

In a standard multiple regression analysis, the five HEVI predictors accounted for $35.9 \%$ of the variance in overall GPA and produced a statistically significant model, $F(5,300)=33.56, p$ $<.001$. Four of the five predictors, Achievement Value $(t=$ $10.79, p=.001)$, Achievement Obstacles $(t=3.59, p=.001)$, Family Expectations $(t=-2.86, p=.004)$, and General Education Value $(t=2.00, p=.046)$ were statistically significant contributors to the model.

\section{Gender Comparison}

Scores for men and women on each of the subscales were compared using independent-sample $t$-tests, and effect sizes were computed using Cohen's $d$. Women reported statistically greater scholastic focus, $t(322)=3.10, p=.002, d=0.34,95 \%$ CI $[0.62,2.77]$, and placed greater value on high achievement, $t(320)=2.75, p=.006, d=0.31,95 \%$ CI $[0.41,2.45]$, and general education courses, $t(320)=4.64, p<.001, d=0.50,95 \%$ CI $[1.36,3.35]$ than men. HEVI total-scale score differences were also statistically significant, with women reporting a greater valuing of higher education in general, $t(310)=4.20, p$ $<.001, d=0.48,95 \%$ CI $[3.09,8.54]$. However, there were no statistically significant differences between men and women on perceptions of family expectations, $t(321)=-.32, p=.748$, $95 \%$ CI $[-0.76,0.55]$, or achievement obstacles, $t(322)=.84, p$ $=.401,95 \%$ CI $[-0.54,1.34]$. Finally, women reported higher overall GPAs than men, $t(318)=3.77, p<.001, d=0.44,95 \%$ CI $[0.11,0.34]$.

\section{Study 3: Reliability of HEVI Scores}

The main purpose of Study 3 was to examine the test-retest reliability of scores on the HEVI. The goal of Study 3 was to administer the HEVI twice over a two-week period to a sample of undergraduate students.

\section{Participants and Procedure}

We administered the HEVI to 61 undergraduate students with the intent of having each student complete the HEVI a second time two weeks later. Of the original 61 students, 47 returned for the retest session (20 men and 27 women). Participants ranged in age from 18 to 24 years $(M=19.25, S D=1.50)$ and included 42 Whites, 3 Blacks, 1 Asian, 0 Hispanics, and 1 student self-classified as "Other." Completion times averaged less than five minutes per testing session.

\section{Results}

Two-week retest correlations for the five HEVI scales were as follows: Family Expectations, $r(45)=.85, p<.001$; Scholastic Focus, $r(45)=.76, p<.001$; Achievement Value, $r(45)$ $=.78, p<.001$; General Education Value, $r(45)=.77, p<.001$; and Achievement Obstacles, $r(45)=.80, p<.001$. The two-week retest correlation of the HEVI total-scale score, which was the sum of the 30 item scores, was $r(45)=.85, p$ $<.001$. Retest coefficients at the item level were more variable, and ranged from $r=.37$ to $r=.75$.

\section{Discussion}

Value, in its verb form, refers to the process of appraising the worth of some commodity (Rohan, 2000). The HEVI includes 30 items that measure the value college students place on higher education. Across two undergraduate samples, factor analytic results suggested a five-factor solution was the most parsimonious and theoretically-consistent accounting of variance in HEVI scores. The five facets contributing to subjective worth included Family Expectations, Scholastic Focus, Achievement Value, General Education Value, and Achievement Obstacles. An obvious shortcoming of our work was that only about $10 \%$ of the students we surveyed were nonwhite, and we focused exclusively on traditional-age freshman students. Given that traditional and nontraditional students may have different mindsets (Faust \& Courtenay, 2002; Hermon \& Davis, 2004; Jinkens, 2009) and that value orientations may differ as a function of ethnicity (e.g., Schwartz, 1992; Valencia, 1997), future analyses with other student samples will allow us to explore the generalizability of our findings to more diverse samples.

Cumulatively, our results suggest that the scores on the HEVI possess acceptable reliability with samples of traditional-age university freshmen. Using Cronbach alpha, all internal consistency estimates exceeded .70, suggesting acceptable item interrelatedness. Likewise, all retest reliability coefficients exceeded .70. However, scores on the Family Expectations and Achievement Obstacles subscales were more stable over a two-week period than were scores on the other scales. Item content on the Family Expectations and Achievement Obstacles subscales is interpersonal in nature, and quantifies students' perceptions of others' expectations as well as their behavioral activities that involve significant others. Scores on these scales are likely influenced by long-standing learning histories, particularly where family members are involved, and are less likely to fluctuate over short time intervals. By contrast, the Achievement Value, General Education Value, and Scholastic Focus scales include items that may be more situationally-determined and context-relevant. Scores on these scales may be sensitive to fluctuations in students' recent experiences and the demands of their academic schedules. 
Table 1.

Structure coefficients for the PCA with varimax rotation of the 30 final HEVI items.

\begin{tabular}{|c|c|c|c|c|c|c|}
\hline HEVI Components and Constituent Items & I & II & III & IV & $\mathrm{V}$ & Total Scale \\
\hline \multicolumn{7}{|l|}{ Family Expectations (I) } \\
\hline I must do well in school to satisfy my family. & .85 & -.04 & .06 & -.12 & -.12 & \\
\hline I receive a lot of pressure from family members to do well in school. & .80 & -.09 & .06 & -.07 & -.07 & \\
\hline My family's expectations about my academic achievement are unrealistically high. & .79 & -.05 & -.08 & -.13 & -.11 & \\
\hline My family would be disappointed if I were just an average student. & .72 & -.07 & .28 & -.02 & -.11 & \\
\hline My family's own expectations of my academic achievement are higher than my own. & .65 & -.19 & -.27 & -.08 & -.21 & \\
\hline It is important for me to meet the expectations of my family members. & .60 & .12 & .17 & .12 & .09 & \\
\hline \multicolumn{7}{|l|}{ Scholastic Focus (II) } \\
\hline I only study when it is absolutely necessary (r). & -.08 & .76 & .07 & .18 & .07 & \\
\hline I usually put off studying until the day before a test (r). & -.02 & .76 & .01 & .05 & .08 & \\
\hline I find other things to do instead of studying (r). & .04 & .75 & .06 & -.03 & .13 & \\
\hline I find it difficult to study when there are more interesting things to do (r). & .03 & .72 & -.11 & .06 & .09 & \\
\hline I rarely study on the weekends (r). & -.12 & .70 & .17 & .06 & -.04 & \\
\hline I party more than I study (r). & -.11 & .59 & .26 & .12 & .05 & \\
\hline \multicolumn{7}{|l|}{ Achievement Value (III) } \\
\hline High grades are important to me. & .06 & .02 & .77 & .09 & .03 & \\
\hline I almost always get one of the top grades in a class. & -.13 & .05 & .71 & .07 & .15 & \\
\hline I place a lot of pressure on myself to do well in school. & .07 & .14 & .70 & .08 & .01 & \\
\hline If someone were to say I was an average student, I would be upset. & .17 & .03 & .69 & .05 & .08 & \\
\hline If I do not receive an "A" on an exam, I am disappointed. & .02 & .00 & .69 & .07 & -.10 & \\
\hline I'm a perfectionist. & .04 & .11 & .59 & .01 & -.11 & \\
\hline \multicolumn{7}{|l|}{ General Education Value (IV) } \\
\hline I should only have to take courses in my major. & -.08 & .12 & -.02 & .83 & .07 & \\
\hline General education requirements are a waste of my time (r). & -.11 & .11 & -.04 & .82 & .05 & \\
\hline I understand why I am required to take a variety of courses to graduate. & -.08 & -.05 & .01 & .72 & .11 & \\
\hline Taking classes outside my area(s) of interest is a valuable experience. & .01 & -.02 & .18 & .70 & .07 & \\
\hline Most of what I learn in school is not useful (r). & -.06 & .29 & .08 & .48 & .14 & \\
\hline I love school. & .01 & .11 & .21 & .40 & -.06 & \\
\hline \multicolumn{7}{|l|}{ Achievement Obstacles (V) } \\
\hline I would do better in school if other obligations took less of my time (r). & .03 & -.05 & -.01 & .05 & .77 & \\
\hline Work-related activities interfere with my schoolwork (r). & .01 & -.07 & -.02 & .04 & .72 & \\
\hline It's hard to focus on school when I have so much else to do (r). & -.02 & .23 & -.08 & -.05 & .68 & \\
\hline My family or friends make it hard for me to succeed in school (r). & -.29 & .22 & .13 & .13 & .54 & \\
\hline Family responsibilities make it difficult for me to do well in school (r). & -.29 & .04 & .00 & .25 & .48 & \\
\hline $\begin{array}{l}\text { Someone close to me (for example, boyfriend, girlfriend, husband, wife) makes it } \\
\text { difficult for me to do well in school (r). }\end{array}$ & -.17 & .27 & .04 & .09 & .47 & \\
\hline Mean & 12.97 & 9.98 & 14.28 & 13.16 & 14.05 & 62.36 \\
\hline Standard deviation & 2.98 & 4.95 & 4.68 & 4.67 & 4.28 & 11.89 \\
\hline Coefficient alpha & .84 & .82 & .79 & .77 & .71 & .75 \\
\hline \multicolumn{7}{|l|}{ Component correlation matrix } \\
\hline I & - & & & & & \\
\hline II & .05 & - & & & & \\
\hline III & .35 & .20 & - & & & \\
\hline IV & .03 & .25 & .17 & - & & \\
\hline $\mathrm{V}$ & -.07 & .26 & .04 & .22 & - & \\
\hline
\end{tabular}

Note: Lowercase " $\mathrm{r}$ " indicates reverse-scored item. Primary structure coefficients are in boldface. 
In the second item tryout, we examined the relationship between HEVI scores and overall GPA. As hypothesized, higher scores on Family Expectations, Scholastic Focus, Achievement Value, and General Education Value were related to higher GPAs. Achievement Obstacles were inversely related to GPA because higher scores on this scale reflect fewer perceived obstacles to achievement. Therefore, students who valued earning high grades, valued becoming well educated across curricular boundaries, and believed that outside obstacles would not impede their scholastic success had higher GPAs than students who held contrasting beliefs. Likewise, HEVI total scores were positively associated with overall GPAs. These findings lend support for the construct validity of scores on the inventory.

When the five HEVI subscales were regressed on self-reported GPA, $35.9 \%$ of the variance in overall GPA was accounted for. An obvious limitation of these analyses is that the self-reported current GPAs of second-semester freshmen served as the criterion. Such reports are subject to memory biases and errors. In addition, because of sample restrictions, students' GPAs necessarily reflected only one semester's worth of course grades. Future criterion-related studies of the HEVI should use grade point averages documented by the university that include grades from the entire year.

Another limitation is that the studies did not directly assess the degree to which HEVI scores incrementally improved prediction of freshman academic performance relative to other standardized instruments of academic proficiency (e.g., SAT and ACT scores). Measures of achievement-related psychological variables, such as control expectancies and academic self-concept, have been shown to enhance predictive accuracy over and above scores on traditional measures, particularly in minority students and students with lower pre-admission criteria (Cone \& Owens, 1991; Gerardi, 1990). Given the ambiguous predictive validity of traditional academic measures, particularly for lower-performing, disadvantaged, or minority students (e.g., Farver, Sedlacek, \& Brooks, 1975; Kanoy, Wester, \& Latta, 1989; Sedlacek, 2005), future studies will examine the degree to which HEVI scores can incrementally improve accuracy in prediction of academic achievement.

We also found evidence that women placed more value on making studying a priority, earning high grades, and becoming well educated across curricular boundaries than men. Given these differences, and the hypothesized relations between HEVI scores and GPA, we were not surprised to learn that women also had higher self-reported GPAs than men. Gender-related differences, particularly in achievement-related choices in math, pervade the task value literature (e.g., Eccles, 1985; Lupart et al., 2004). Eccles et al. $(1983,1984)$ proposed that task value is a function of a person's needs, goals, and self-perceptions. Therefore, one possibility is that scores on the HEVI may be affected by gender-role socialization and personal goals. As examples, men may exhibit single-minded devotion to a single goal, such as career success (Eccles, Barber, \& Jozefowicz, 1999), whereas women may focus on career training as well as general intellectual improvement (Green \& Hill, 2003; Schab, 1974). As such, women, who have multiple roles and multiple goals (Eccles et al., 1999), may place a higher value on demonstrating competence in several academic domains simultaneously than men.

\section{Conclusion}

According to Rokeach (1973), "the value concept, more than any other, should occupy a central position... able to unify the apparently diverse interests of all the sciences concerned with human behavior" (p. 3). Although Rokeach made this statement nearly 40 years ago, empirical investigations of the values construct are relatively limited at the university level and ample opportunities for inspection and discovery remain. We presented preliminary evidence for the factorial validity, concurrent validity, and reliability of scores on the HEVI, an inventory designed to measure the value college students place on higher education. At the present time, however, we have not collected data regarding the discriminant validity of HEVI scores nor have we examined the relationship between HEVI scores and attrition. Future investigations will aim to provide further evidence of the construct validity of HEVI scores and will assess factor invariance across gender and culturally diverse groups.

\section{References}

American Educational Research Association, American Psychological Association, \& National Council on Measurement in Education (1999). Standards for educational and psychological testing. Washington DC: American Educational Research Association, American Psychological Association, \& National Council on Measurement in Education.

Atkinson, J. W. (1957). Motivational determinants of risk-taking behavior. Psychological Review, 64, 359-372. doi:10.1037/h0043445

Ausubel, D. P. (1968). Educational psychology: A cognitive view. New York, NY: Holt, Rinehart and Winston.

Battle A., \& Wigfield, A. (2003). College women's value orientations toward family, career, and graduate school. Journal of Vocational Behavior, 62, 56-75. doi:10.1016/S0001-8791(02)00037-4

Berndt, T. J., \& Miller, K. E. (1990). Expectancies, values, and achievement in junior high school. Journal of Educational Psychology, 82, 319-326. doi:10.1037/0022-0663.82.2.319

Bong, M. (2001). Role of self-efficacy and task-value in predicting college students' course performance and future enrollment intentions. Contemporary Educational Psychology, 26, 553-570.

Cattell, R. B. (1966). The scree test for the number of factors. Multivariate Behavioral Research, 1, 245-276.

Chiu, C.-M., Sun, S.-Y., Sun, P.-C., \& Ju, T. L. (2007). An empirical analysis of the antecedents of web-based learning continuance. Computers and Education, 49, 1224-1245.

Comrey, A. L. (1973). A first course in factor analysis. New York, NY: Academic Press.

Cone, A. L., \& Owens, S. K. (1991). Academic and locus of control enhancement in a freshman study skills and college adjustment course. Psychological Reports, 68, 1211-1217. doi:10.2466/PRO.68.4.1211-1217

Eccles, J. S. (1985). Why doesn't Jane run? Sex differences in educational and occupational patterns. In F. D. Horowitz, \& M. O'Brien (Eds.), The gifted and talented: Developmental perspectives (pp. 251-295). Washington DC: USical Association.

Eccles, J. S., Adler, T. F., Futterman, R., Goff, S. B., Kaczala, C. M., Meece, J. L., \& Midgley, C. (1983). Expectancies, values, and academic behaviors. In J. T. Spence (Ed.), Achievement and achievement motivation (pp. 75-146). San Francisco: W. H. Freeman.

Eccles, J. S., Adler, T., \& Meece, J. L. (1984). Sex differences in achievement: A test of alternate theories. Journal of Personality and Social Psychology, 46, 26-43.

Eccles, E. S., Barber, B., \& Jozefowicz, D. (1999). Linking gender to educational, occupational, and recreational choices: Applying the Eccles et al. model of achievement-related choices. In W. B. Swann, J. H. Langlois, \& L. A. Gilbert (Eds.), Sexism and stereotypes in modern society: The gender science of Janet Taylor Spence (pp. 153-192). Washington DC: American Psychological Association.

Eccles, J. S., Vida, M. N., \& Barber, B. (2004). The relation of early adolescents' college plans and both academic ability and task-value beliefs to subsequent college enrollment. Journal of Early Adolescence, 24, 63-77. 
Eccles, J. S., \& Wigfield, A. (1995). In the mind of the actor: The structure of adolescents' academic achievement task values and expectancy-related beliefs. Personality and Social Psychology Bulletin, 21, 215-225. doi: 10.1177/0146167295213003

Eccles, J. S., \& Wigfield, A. (2002). Motivational beliefs, values, and goals. Annual Review of Psychology, 53, 109-132.

Farver, A. S., Sedlacek, W. E., \& Brooks, G. C., Jr. (1975). Longitudinal predictions of university grades for blacks and whites. Measurement and Evaluation in Guidance, 7, 243-250.

Faust, D. F., \& Courtenay, B. C. (2002). Interaction in the intergenerational freshman class: What matters. Educational Gerontology, 28, 401-422. doi:10.1080/03601270290081362

Feather, N. T. (1982). Expectancy-value approaches: Present status and future directions. In N. T. Feather (Ed.), Expectations and actions: Expectancy-value models in psychology. Hillsdale, NJ: Erlbaum.

Feather, J. T. (1988). Values, valences, and course enrollment: Testing the role of personal values within an expectancy-value framework. Journal of Educational Psychology, 80, 381-391. doi:10.1037/0022-0663.80.3.381

Ferry, T. R., Fouad, N. A., \& Smith, P. L. (2000). The role of family context in a social cognitive model for career-related choice behavior A math and science perspective. Journal of Vocational Behavior, 57, 348-364.

Findley, M. J., \& Cooper, H. M. (1983). Locus of control and academic achievement: A literature review. Journal of Personality and Social Psychology, 44, 419-427. doi:10.1037/1022-3514.44.2.419

Floyd, F. J., \& Widaman, K. F. (1995). Factor analysis in the development and refinement of clinical assessment instruments. Psychological Assessment, 7, 286-299. doi:10.1037/1040-3590.7.3.286

Frome, P. M., Alfeld, C. J., Eccles, J. S., \& Barber, B. L. (2006). Why don't they want a male-dominated job? An investigation of young women who changed their occupational aspirations. Educational Research and Evaluation, 12, 359-372. doi: $10.1080 / 13803610600765786$

Frome, P. M., \& Eccles, J. S. (1998). Parents' influence on children's achievement-related perceptions. Journal of Personality and Social Psychology, 74, 435-452. doi:10.1037/0022-3514.74.2.435

Gerardi, S. (1990). Academic self-concept as a predictor of academic success among minority and low-socioeconomic status students. Journal of College Student Development, 31, 402-407.

Gorsuch, R. (1997). Exploratory factor analysis: Its role in item analysis. Journal of Personality Assessment, 68, 532-560.

Green, R. J., \& Hill, J. H. (2003). Sex and higher education: Do men and women attend college for different reasons? College Student Journal, 37, 557-563.

Guadagnoli, E., \& Velicer, W. F. (1988). Relation of sample size to the stability of component patterns. Psychological Bulletin, 103, 265275. doi:10.1037/0033-2909.103.2.265

Haynes, S. N., Richard, D. C. S., \& Kubany, E. S. (1995). Content validity in psychological assessment: A functional approach to concepts and methods. Psychological Assessment, 7, 238-247. doi:10.1037/1040-3590.7.3.238

Hermon, D. A., \& Davis, G. A. (2004). College student wellness: A comparison between traditional- and nontraditional-age students. Journal of College Counseling, 24, 32-39.

Husman, J., \& Lens, W. (1999). The role of the future in student motivation. Educational Psychologist, 34, 113-125.

Jacobs, N., \& Harvey, D. (2005). Do parents make a difference to children's academic achievement? Differences between parents of higher and lower achieving students. Educational Studies, 31, 431-448. doi:10.1080/03055690500415746

Jacobs, J. E., Lanza, S., Osgood, D. W., Eccles, J. S., \& Wigfield, A. (2002). Changes in children's self-competence and values: Gender and domain differences across grades one through twelve. Child Development, 73, 509-527.

Jinkens, R. C. (2009). Nontraditional students: Who are they? College Student Journal, 43, 979-987.

Jozefowicz, D. M., Barber, B. L., \& Eccles, J. S. (1993, March). Adolescent work-related values and beliefs: Gender differences and relation to occupational aspirations. Biennial Meeting of the Society for Research on Child Development, New Orleans.

Kaiser, H. F. (1958). The varimax criterion for analytic rotation in factor analysis. Psychometrika, 23, 187-200.
doi:10.1007/BF02289233

Kalechstein, A. D., \& Nowicki, S. Jr. (1997). A meta-analytic examination of the relationship between control expectancies and academic achievement: An 11-year follow-up to Findley and Cooper. Genetic, Social, and General Psychology Monographs, 123, 27-56.

Kanoy, K. W., Wester, J., \& Latta, M. (1989). Predicting college success of freshmen using traditional, cognitive, and psychological measures. Journal of Research and Development in Education, 22, 65-70.

Kauffman, D. F., \& Husman, J. (2004). Effects of time perspective on student motivation: Introduction to a special issue. Educational Psychology Review, 16, 1-7.

Lupart, J. L., Cannon, E., \& Telfer, J. A. (2004). Gender differences in adolescent academic achievement, interests, values and life-role expectations. High Ability Studies, 15, 25-42.

Meece, J. L., Wigfield, A., \& Eccles, J. S. (1990). Predictors of math anxiety and its consequences for young adolescents-course enrollment intentions and performance in mathematics. Journal of Educational Psychology, 82, 60-70.

Nagy, G., Trautwein, U., Baumert, J., Köller, O., \& Garrett, J. (2006). Gender and course selection in upper secondary education: Effects of academic self-concept and intrinsic value. Educational Research and Evaluation, 12, 323-345.

Neuville, S., Frenay, M., Schmitz, J., Boudrenghien, G., Noël, B., \& Wertz, V. (2007). Tinto's theoretical perspective and expectancyvalue paradigm: A confrontation to explain freshmen's academic achievement. Psychologica Belgica, 47, 31-50.

Novak, J. D. (1977). A theory of education. New York, NY: Cornell University Press.

Nunnally, J. C., \& Bernstein, I. H. (1994). Psychometric theory (3rd ed.). New York, NY: McGraw-Hill.

Piaget, J. (1928/2009). Children's understanding of causality. British Journal of Psychology, 100, 207-224. doi: $10.1348 / 000712608 \times 336059$

Platt, C. W. (1988). Effects of causal attributions for success of first-term college performance: A covariance structure model. Journal of Educational Psychology, 80, 569-578. doi:10.1037/0022-0663.80.4.569

Pollio, H. R., Eison, J. A., \& Milton, O. (1988). College grades as an adaptation level phenomenon. Comtemporary Educational Psychology, 13, 146-156. doi:10.1016/0361-476X(88)90015-X

Reynolds, J. R., \& Burge, S. W. (2008). Educational expectations and the rise in women's postsecondary attainments. Social Science Research, 37, 485-499. doi:10.1016/j.ssresearch.2007.09.002

Rheinberg, F., Vollmeyer, R., \& Rollett, W. (2000). Motivation and action in self-regulated learning. In M. Boekaerts, P. R. Pintrich, \& M. H. Zeidner (Eds.), Handbook of self-regulation (pp. 503-529). San Diego, CA: Academic Press.

Rohan, M. J. (2000). A rose by any name? The values construct. Personality and Social Psychology Review, 4, 255-277.

Rokeach, M. (1973). The nature of human values. New York, NY: Free Press.

Rokeach, M. (1979). From the individual to institutional values with special reference to the values of science. In M. Rokeach (Ed.), Understanding human values (pp. 47-70). New York, NY: Free Press.

Rotter, J. B. (1954). Social learning and clinical psychology. New York, NY: Prentice-Hall.

Schab, F. (1974). Reasons for attending college as reported by female students in a southern university. Florida Journal of Educational Research, 16, 55-58.

Schwartz, S. H. (1992). Universals in the content and structure of values: Theoretical advances and empirical tests in 20 countries. In M. P Zanna (Ed.), Advances in experimental social psychology (Vol. 25, pp. 1-65). San Diego, CA: Academic Press.

Schwartz, S. H. (2010). Basic values: How they motivate and inhibit prosocial behavior. In M. Mikulincer, \& P. R. Shaver (Eds.), Prosocial motives, emotions, and behavior: The better angels of our nature (pp. 221-241). Washington, DC: American Psychological Association.

Sedlacek, W. E. (2005). The case for noncognitive measures. In W. J. Camara \& E. W. Kimmel (Eds.), Choosing students: Higher education admissions tools for the 21st century (pp. 177-193). Mahwah, NJ: Lawrence Erlbaum. 
Simpkins, S. D., Davis-Kean, P. E., \& Eccles, J. S. (2006). Math and science motivation: A longitudinal examination of the links between choices and beliefs. Developmental Psychology, 42, 70-83. doi:10.1037/0012-1649.42.1.70

Stevens, J. (2002). Applied multivariate statistics for the social sciences (4th ed.), Mahwah, NJ: Lawrence Erlbaum.

Updegraff, K. A., Eccles, J. S., Barber, B. L., \& O’Brien, K. M. (1996). Course enrollment as self-regulatory behavior: Who takes optional high school math courses? Learning and Individual Differences, 8, 239-259.

Valencia, A. A. (1997). Anglo-American and Mexican American students' estimation of value placed on higher educational attainments by significant persons in their lives. Journal of Multicultural Counseling and Development, 25, 269-280.

VanZile-Tamsen, C. (2001). The predictive power of expectancy of success and task value for college students' self-regulated strategy use. Journal of College Student Development, 42, 233-241.

Watt, H. M. G. (2006). The role of motivation in gendered educational and occupational trajectories related to maths. Educational Research and Evaluation, 12, 305-322. doi:10.1080/13803610600765562

Watt, H. M. G., Eccles, J. S., \& Durik, A. M. (2006). The leaky mathematics pipeline for girls: A motivational analysis of high school enrolments in Australia and the USA. Equal Opportunities International, 25, 642-659. 